\title{
ORGANIZAÇÕES COMPLEXAS E CONFIABILIDADE ORGANIZACIIONAL: REFLEXÕ̉ES SOBRE AS HRO - HIGH RELIABILITY ORGANIZATIONS ${ }^{1}$
}

\section{COMPLEX ORGANIZATIONS AND RELIABILITY ORGANIZACIIONAL: REFLECTIONS ON THE HRO - HIGH RELIABILITY ORGANIZATIONS}

\author{
Paulo Muro $^{2}$ \\ Victor Meyer $\mathrm{Jr}^{3}$
}

RESUMO: O trabalho das organizações tem merecido crescente atenção dos teóricos desta área por suas implicações econômicas, sociais, tecnológicas, políticas ou ambientais. Como unidades de produção as organizações combinam recursos naturais, materiais, humanos e tecnológicos ao colocar bens e serviços à disposição da sociedade. A natureza do produto/serviço e a complexidade do processo produtivo, examinado como sistema sócio-técnico, fazem com que falhas ou acidentes em suas atividades tenham repercussões indesejáveis às organizações, aos seus integrantes, bem como ao meio ambiente e à sociedade. $\mathrm{O}$ objetivo deste trabalho é examinar as organizações vistas como sistemas complexos que se caracterizam por operações de alto risco com baixa ou nula taxa de acidentes e identificadas como high reliability organizations. Trata-se de um ensaio teórico que se fundamenta nas principais teorias baseadas no estudo de sistemas complexos e confiabilidade, como Normal Accidents Theory (NAT) (Charles Perrow) e High Reliability Theory (HRT) (Karl Weick). O trabalho aborda questões relacionadas aos riscos decorrentes de falhas e erros de operações de organizações que podem provocar acidentes com efeitos desastrosos à vida humana e ao próprio ambiente. É examinada a relevância crescente da análise de sistemas complexos e das características das organizações que operam estes sistemas complexos e de alto risco, mas que apresentam alto grau de confiabilidade. As conclusões enfatizam que atribuir à uma organização o status de "altamente confiável" requer análise cuidadosa, por se tratar de questão situacional em que aspectos de natureza comportamental e técnica possuem uma forte influencia em detrimento de outras dimensões organizacionais.

PALAVRAS CHAVES: Organizações, Sistemas Complexos e Confiabilidade Organizacional

ABSTRACT: The work of organizations has experienced a growing attention from organizational theorists due to the economic, social, technological, political or environment interests. As productive units they combine natural, material, human, and technological resources in order to offer goods and services to society. The nature of their products and services along with the complexity of the production process, classified as a sociotechnical system, have brought about failures and accidents in their activities with undesirable impact to organizations and their employees as well as to the environment and society. The purpose of this paper is to examine organizations as complex systems characterized by high risk operation with low or none identified accidents in their production units and known as high reliability organizations. This work can be characterized as an essay and it is based on the main theories on complex systems and organizational reliability like Normal Accidents Theory (NAT) (Charles Perrow) and High Reliability Theory (HRT) (Karl Weick). The paper approaches questions related to risks due to operational failures and errors that can cause accidents with dangerous effects that may threat human lives and the environment. The analysis of such complex systems and the characteristics of organizations that operate such complex and high risk system but display high level of reliability is developed. The conclusions stress that to ascribe to a particular organization the status of "high reliability" requires a careful analysis because it implies a situational question in which aspect of behavior or technical nature have a stronger influence than other organizational dimensions.

KEY WORDS: Organizations, Complex Systems and Organizational Reliability

\footnotetext{
${ }^{1}$ Artigo Recebido em 09.03.2011. Revisado por pares em 04.08.2011. Recomendado em 22.08.2011 por Leomar dos Santos Editor. Publicado em 21.09.2011.

Organização Responsável pelo periódico: Universidade regional de Blumenau - FURB - www.furb.br/rn
}

\footnotetext{
${ }^{2}$ Pontifícia Universidade Católica - PUC/PR - paulo.muro@terra.com.br

${ }^{3}$ Pontifícia Universidade Católica - PUC/PR - vmeyer@matrix.com.br
} 


\section{INTRODUÇÃO}

A sociedade é estruturada por meio de organizações de modo que o seu funcionamento, assim como a vida das pessoas, depende essencialmente do desempenho organizacional. As organizações estão tão inseridas na vida das pessoas que levaram Etzioni (1989) a observar que nascemos, passamos a maior parte de nossa vida e morremos em organizações.

Critérios de afinidade orientam a formação da organização estabelecendo sua composição, objetivos e modo de funcionamento. Meyer Jr. (2007) ressalta que as organizações tiveram rápida disseminação na sociedade e que o agrupamento das pessoas compondo organizações tem possibilitado o desenvolvimento da especialização organizacional.

Essa dependência que a sociedade desenvolveu em relação às organizações impulsionou o desenvolvimento e a sofisticação de métodos de operação e de gestão e influenciou a adoção de tecnologias e a especialização das organizações.

Segundo Etzioni (1989), a sociedade moderna valorizou o racionalismo e a eficiência, o que se reflete também nas organizações. Neste contexto a eficácia organizacional passa a ter, cada vez mais, maior importância na medida em que as pessoas vão se tornando dependentes dos serviços e produtos gerados pelas organizações. No entanto o mesmo autor observa que a reduzida eficácia é uma característica frequente nas organizações. Muitas que adotaram a "excelência" como referência para sua operação, não a mantiveram pela falta de capacidade de aprendizado e, além disso, muito do que foi adotado ficou limitado a reações diante de pressões competitivas (QUINELLO; NUNES, 2004)

Algumas organizações, chamadas complexas, possuem particularidades que exigem especial atenção e análise mais acurada (MEYER JR, 2007). Essas organizações, cuja complexidade decorre da natureza e do processo de produção de seus produtos ou serviços estão sujeitas, a exemplo de outras organizações, a falhas, imprevistos, irregularidades com implicações no seu desempenho. Neste particular a confiabilidade organizacional torna-se aspecto essencial para usuários ou beneficiários de organizações complexas, assim como para a própria sociedade.

Nesse tipo de organização as falhas não são permitidas em suas operações. Quando existentes, as falhas apresentam sérias repercussões no próprio sistema produtivo com impacto nos produtos ou serviços prestados às pessoas, à própria organização, à sociedade, assim como ao meio ambiente.

Os exemplos mais comuns desse tipo de organização referem-se às usinas nucleares, controle e operações de tráfego aéreo, plataformas de petróleo, expedições espaciais, submarinos nucleares, porta-aviões, unidades hospitalares de urgência, sistemas de transporte ferroviário, usinas elétricas, indústrias químicas, sistema de abastecimento de água, minas e tantas outras que se tornaram essenciais por seu tipo de serviço ou produto.

O que leva as pessoas a confiarem em uma organização? Por que as pessoas se sentem confiantes ao submeterem-se a uma cirurgia sofisticada num hospital? É fantástico o número de pessoas que diariamente optam por utilizar o metrô como meio de transporte na malha urbana das grandes cidades. Da mesma forma optam por viajar em aviões ou trens. Essas pessoas depositam confiança nas organizações que prestam esses serviços, embora não raro é o registro de acidentes que provocam mortes e perdas.

Falhas na operação dos trens e de metrô podem não chegar a causar mortes, mas uma paralisação por algumas horas de suas linhas pode trazer o caos a uma metrópole provocando perdas incalculáveis. A interrupção, por alguns dias, da distribuição de combustível ou de energia elétrica, os chamados apagões, provoca abalos significativos na economia de uma 
região ou do próprio país, como ocorreu no Brasil em 10 de novembro de 2009, ocasião em que 18 estados foram atingidos pela falta de energia elétrica.

Por outro lado, o vazamento de substância radioativa de uma unidade que opera energia nuclear pode provocar milhares de mortes e destruição do meio ambiente, além de contaminações que perduram por centenas de anos ameaçando gerações presentes e futuras. Dois exemplos são clássicos: a explosão do reator da Usina de Chernobyl na Ucrânia, considerado o maior desastre da história, ocorrido em 1986 e o vazamento nuclear da Usina de Three Mile Island nos EUA, em 1979.

Como destacam Leveson et al. (2009), as mesmas tecnologias que proporcionam prosperidade são também aquelas que podem causar problemas com sérias consequências às pessoas e à sociedade. Mesmo que os erros e falhas não causem milhares de mortes, que costumam ocorrer em catástrofes, elas também podem causar danos significativos às infraestrururas vitais (PERROW, 2004).

\section{METODOLOGIA}

Este trabalho se caracteriza como ensaio teórico a partir da revisão da literatura que aborda o tema confiabilidade das organizações. Buscou-se na literatura identificar o que existe de consenso ou polêmico sobre o assunto.

Conforme Severino (2007), um ensaio teórico é um estudo formal, discursivo que consiste numa exposição lógica e reflexiva possibilitando interpretações pessoais. Como contribuição ao conhecimento, o ensaio teórico, deve provocar reflexões inovadoras na área pesquisada (USP, 2011).

\section{COMPLEXIDADE}

Para o desenvolvimento do tema da confiabilidade, e também sobre os acidentes, são apresentadas a seguir algumas considerações sobre a teoria organizacional que trata da complexidade. A título de delimitação, faz-se necessário esclarecer que não há aqui a pretensão de abordar o tema em maior profundidade, o que seria impraticável em função da amplitude e da dificuldade que o tema impõe. Segundo Gershenson \& Heylighen (2005), a complexidade é ela própria um conceito complexo. As próximas considerações se restringem aos aspectos da complexidade que diretamente implicam as teorias sobre acidentes e sobre confiabilidade.

No entendimento de Gilpin (2005), a teoria da complexidade mostra-se adequada no estudo e na gestão de crises organizacionais que frequentemente oferecem oportunidades de aprendizado para os que se envolveram com as crises. No entanto o mesmo autor observa que normalmente é feita uma abordagem linear, e o foco fica na formulação e execução de um conjunto detalhado de procedimentos que compõem um plano de crises, e assim se inibe a oportunidade de aprendizado aumentando a probabilidade de crises subsequentes.

No contexto epistemológico, o tema complexidade não havia despertado a devida atenção entre os estudiosos, conforme explica Morin (2003). Esse mesmo autor menciona ainda Gaston Bechelard, como sendo uma exceção, que considerando fundamental a questão da complexidade, teria afirmado "que não há nada simples na natureza; só há o simplificado". Mas foi, ainda segundo Morin (2003), a partir da cibernética e da teoria dos sistemas que a complexidade começou a ganhar importância.

$\mathrm{Na}$ perspectiva do pensamento da complexidade o conhecimento decorre de uma representação da realidade que depende também das percepções do próprio observador, tornando-se, então, subjetivo (PRIM et al. 2008). Segundo Morin (2003), o estudo da 
complexidade procura compreender a relação entre as partes ou elementos dos sistemas, sem desvincular umas das outras, procurando a compreensão multidimensional.

Para existir um sistema complexo duas ou mais partes distintas são agrupadas de tal modo que se torna difícil separá-las. Caso sejam separadas para análise individual, não será então possível compreender a complexidade uma vez que esta complexidade está na relação entre as partes (GERSHENSON; HEYLIGHEN, 2005). Esses mesmos autores argumentam que os elementos de um sistema complexo se unem de tal forma que a mudança em um determina a propagação para os demais componentes, sendo que essa propagação irá alcançar inclusive o próprio componente que iniciou o processo de propagação.

Num sistema complexo os elementos interagem entre si, como também com o ambiente, continuamente de modo dinâmico e não linear, e o próprio sistema altera sua composição básica, caracterizando a propriedade de auto-organização que na maioria das vezes é suficiente para classificar um sistema como complexo (GILPIN, 2005). Esse autor afirma também que a interação dos elementos produz aprendizado por meio de um processo de realimentação de informação (feedback) resultando na coevolução do sistema.

Não se pode compreender um sistema complexo pelo reducionismo, buscando entender o todo somente examinando as características das partes, ou mesmo negligenciando as partes visando compreender só pela observação do todo. Essa impossibilidade se dá pelo princípio hologramático dos sistemas complexos em que não apenas a parte está no todo, mas também o todo está na parte (MORIN, 2003). Portanto o sistema passa ser mais que a simples soma das partes, e cada elemento do sistema é, como parte do sistema, mais do que é quando de forma isolada.

Morin (2003) considera também o princípio da recursividade presente nos sistemas complexos, em que os efeitos de um sistema são também suas próprias causas e sua própria produção, caracterizando os problemas da autoprodução e da auto-organização.

Conforme Gilpin (2005), um sistema complexo não tem suas fronteiras bem definidas além de elas não serem estáticas. Morgan (1996) explica a organização como um sistema em que cada área do ambiente interage com a organização, fazendo parte da própria organização. Por exemplo, diversos atores do mercado em que a organização atua, como fornecedores, mão de obra, coletividade, concorrentes, entre outros, fazem parte do mesmo sistema em que se define a organização, causando interdependência e provocando consequências. Assim, as fronteiras da organização podem ser consideradas como referências relativas.

Segundo Prim et al.(2008), nas teorias organizacionais baseadas no pensamento clássico, não são consideradas as relações da organização com o ambiente, como também as relações existentes entre as partes da organização. Com base no pensamento sistêmico, a evolução é decorrente de reações às mudanças do ambiente para que seja restabelecido o equilíbrio do sistema. Quer dizer, é um processo reativo que desconsidera a autonomia dos indivíduos na organização, e a autonomia da organização ambiente. Por outro lado, as teorias baseadas no pensamento da complexidade compreendem a organização como um processo que emerge das relações entre indivíduos e ao mesmo tempo em que a organização influencia o ambiente e é também influenciada por esse ambiente.

A organização pode ser explicada pelo que produz um sistema complexo como decorrência da disposição relacional que liga, transforma, mantém ou produz componentes, indivíduos ou acontecimentos (SERVA 1992).

As pesquisas sobre a confiabilidade que são suportadas pela teoria Normal Accidents Theory (NAT) ou High Reliability Theory (HRT), comentadas mais adiante, têm como foco de seus estudos sistemas e organizações complexas.

\subsection{ARTICULAÇÃO}


O termo que tem sido frequentemente usado em inglês para determinar como é a articulação entre as partes de um sistema é couple e então coupled. Pode-se traduzir como conexão, acoplagem, ou como adotado neste texto, articulação, entre outras. Assim, as formas como os elementos se unem, variam de firmemente articulados (tight coupled, em inglês) até frouxamente articulado (loosely coupled).

Weick (1976) define "frouxamente articulado" (loosely coupled) como uma situação em que os elementos são sensíveis às relações entre eles, mas mantêm evidências de separação e distinção de identidade. Para esse mesmo autor, um sistema frouxamente articulado é evidente quando os elementos afetem um ao outro, em dado momento, ao invés de continuamente, superficialmente em vez de significativamente, e indireta e eventualmente em vez de imediato.

Perrow (1999) argumenta que diferentemente do que ocorre em sistemas frouxamente articulados, em que são possíveis os atrasos ou retardos, os sistemas fortemente articulados são mais dependentes do tempo e não oferecem possibilidade de interrupções para correções ou modificações de sua produção. O exemplo dado pelo autor é de uma indústria química em que as reações são instantâneas, não podendo haver retardos. Para Perrow (1999), em sistemas fortemente articulados, as sequências são rígidas dificultando alternativas ao modo de execução.

Nos sistemas em que as interações são complexas e firmemente articuladas, a implicações entre os elementos são evidentes de modo que uma modificação em um elemento desencadeia uma onda de modificações no sistema. Leveson et al. (2009) observam que nos sistemas firmemente articulados não há tempo suficiente para a compreensão e controle de eventos que possam desencadear incidentes ou acidentes. Esses mesmos autores destacam que a criação de recursos para evitar as falhas pontuais ou a introdução de elementos redundantes, acaba por causar maior complexidade e por inserir novos elementos também fortemente articulados no sistema, o que torna ainda mais difícil a tentativa de evitar e controlar eventuais falhas.

As principais diferenças entre sistemas fortemente e frouxamente articulados estão apresentadas no Quadro 1, a seguir:

\begin{tabular}{|l|l|}
\hline \multicolumn{1}{|c|}{ Fortemente articulados } & \multicolumn{1}{c|}{ Frouxamente articulados } \\
\hline Sem possibilidade de retardos nos processos & Possibilidades de retardos nos processos \\
\hline Sequência das atividades não pode ser alterada & $\begin{array}{l}\text { Possibilidade de alteração das sequências } \\
\text { com que as atividades são executadas }\end{array}$ \\
\hline Único método para alcançar os objetivos & Vários métodos para alcançar os objetivos \\
\hline $\begin{array}{l}\text { Pouca folga para abastecimentos, troca de } \\
\text { equipamentos ou de pessoal }\end{array}$ & Razoável folga para manutenção de recursos \\
\hline $\begin{array}{l}\text { Proteções e redundâncias planejadas no design do } \\
\text { processo }\end{array}$ & Proteções e redundâncias ocasionais \\
\hline $\begin{array}{l}\text { Substituições de fornecedores, equipamento e } \\
\text { pessoal, limitadas e planejadas }\end{array}$ & $\begin{array}{l}\text { Substituições de recursos ocasionais são } \\
\text { viáveis }\end{array}$ \\
\hline
\end{tabular}

Quadro 1 - Distinções entre sistemas fortemente e frouxamente articulados. Fonte: Perrow (1999, p. 96).

Uma vez que o sistema apresenta falhas, é normal a necessidade de proceder a reparos e recuperações, muitas vezes até para evitar acidentes ou a propagação de falhas para outras 
partes do sistema. Em um sistema fortemente articulado, as intervenções para recuperar ou corrigir falhas são extremamente limitadas, em função do pequeno ou nulo intervalo de tempo entre operações, da invariabilidade da sequência das atividades e da falta de folga no processo (PERROW, 1999).

Ao comentar falhas que provocaram o acidente aéreo do voo Gol número 1907, em setembro de 2006, considerado o maior do gênero no Brasil, a jornalista Eliane Cantanhede destacou que "sete minutos para avisar, sete minutos em aviação é muito tempo..." (TRAGÉDIA, 2007). O comentário evidencia a condição de inexistência de folga em sistemas fortemente articulados, que nesse caso, foi fatal para a ocorrência do acidente.

\section{NORMAL ACCIDENTS THEORY - NAT}

Estudos sobre Normal Accidents Theory (NAT) foram trazidos para enriquecer a análise das organizações tendo como foco o exame das catástrofes, como Chernobyl, Three Mile Island, Bhopal, Challenger, dentre outras. Após examinar o acidente ocorrido em $28 \mathrm{de}$ março de 1979 na central nuclear de Three Mile Island, na Pensilvânia - USA, Charles Perrow identificou semelhanças de ocorrências em outras organizações, em particular nas universidades, especificamente quanto à presença de pequenos erros que se sobrepõem, inesperadamente, trazendo consequências imprevisíveis (Perrow, 2004).

Além de constatar que ambas as organizações se caracterizavam como sistemas complexos Perrow (2004) observou semelhanças e diferenças entre elas. As universidades, como "sistemas frouxamente articulados", não apresentavam um desencadear de falhas a partir de um erro ou falha inicial. As falhas nas universidades também não causariam catástrofes como um acidente em uma usina nuclear. Para Perrow (1999), os acidentes surgem a partir de incidentes ou pequenas falhas de sistemas que desencadeiam outras falhas as quais acabam por comprometer todo o sistema.

Os defensores da Normal Accidents Theory - NAT- argumentam que em sistemas complexos fortemente articulados é normal e esperada a ocorrência de acidentes. Segan (1995) considera que esses argumentos partem de uma premissa pessimista ao argumentar que acidentes graves em sistemas complexos de alta tecnologia são inevitáveis ou, como destaca Perrow (1999), são acidentes "normais" ou esperados.

Leveson et al. (2009), por sua vez, consideram válida a proposição de Perrow da inevitabilidade de acidentes em sistemas complexos e complementam com a ideia de que fazer esforços para prover mais segurança em sistemas fortemente articulados e de interação complexa tende a causar maior complexidade, aumentando a probabilidade de acidentes.

\subsection{HIGH RELIABILITY THEORY (HRT)}

Os primeiros estudos sobre High Reliability Theory $(H R T)$ - teoria da alta confiabilidade - $e$ High Reliability Organizations (HRO) - organizações de alta confiabilidade começaram a emergir a partir das pesquisas organizacionais datadas da década de 1980, inspiradas no trabalho de Charles Perrow (1994). Esse autor, ao abordar a NAT, descreve complexidade e sistemas tecnológicos fortemente articulados como características de empresas consideradas perigosas e de alto risco.

No entendimento de Hopkins (2007), o conceito de High Reliability Organizations (HRO) tem origem na década de 1980, decorrente de pesquisas realizadas na Universidade da Califórnia por pesquisadores como Joseph Morone, Edward Woodhouse, Aaron Wildavsky, Karlene Roberts, Todd La Porte, Paula Consolini, Gene Rochlin, entre outros. Estes pesquisadores observaram que havia muita pesquisa sobre organizações que tinham 
vivenciado desastres, no entanto poucos eram os estudos sobre as organizações que, apesar de atuarem com tecnologia perigosa, desempenhavam suas operações sem histórico de acidentes.

Conforme Segan (1995), a HRT adota pressupostos mais otimistas que os adotados pela NAT. Enquanto a NAT considera normal a ocorrência de acidentes em sistemas perigosos e dependentes de alta tecnologia, a HRT argumenta que mesmo nesses sistemas é possível uma operação segura com baixa ou nula taxa de acidentes.

Leveson et al. (2009) diferenciam os conceitos de segurança e de confiabilidade, os quais são por eles considerados independentes, podendo até ser conflitante em alguns casos. Assim, esses mesmos autores definem confiabilidade como a probabilidade de que um componente funcionar, conforme sua especificação ao longo do tempo, sob determinadas condições. Já segurança é definida como a improbabilidade de ocorrência de perdas inaceitáveis, como são os acidentes. Ao criticar a HRT, Leveson et al. (2009) argumentam que os conceitos confiabilidade e segurança são equivocadamente considerados equivalentes pela HRT.

Algumas organizações são consideradas como altamente confiáveis (high reliability) por apresentarem, consistentemente, segurança por longos períodos, mesmo operando com sistemas tecnológicos de alta complexidade e fortemente articulados. Para Weick e Sutcliffee (2001), essas organizações são mais atentas a sinais de anormalidades, mesmo que estes sinais se apresentem como fracos e, ainda assim, são capazes de perceber o inesperado. Isto faz com que tenham condições de poder tomar decisões efetivas interrompendo o desenvolvimento de uma ação inesperada, que se mostra mais resistente e, desta forma, lograr uma rápida recuperação da condição de normalidade do sistema.

Embora funcionem em ambientes de alto risco e realizem operações de grande complexidade, as HRO têm um desempenho operacional superior, com incidência de erro que se aproxima do zero (JOSLIN MEDEIROS; PINTO, 2009). Desta forma, classificar organizações como HRO, no entendimento de Rochlin (1993), não é uma atribuição elementar. Do ponto de vista do desenvolvimento teórico, é algo necessário que requer rigor e precisão. É necessário clareza na caracterização para que se evite confundir HRO com outras organizações similares em função de alguns aspectos superficiais. Os critérios precisam ser suficientes para que as observações empíricas contribuam para sustentar explicações sobre como uma organização conseguiu altos níveis de confiabilidade em seu desempenho, enquanto, nas mesmas condições, outras organizações falharam.

Após analisar três organizações, Rochlin (1993) identificou algumas características em comum, como operar tecnologias complexas, sujeitas a risco de grande dano à imagem pública, decorrente de erro operacional e sucesso dependente de desempenho confiável, entre outras características. Essas organizações, embora operassem com tecnologia complexa e de alto risco, não tinham histórico de acidentes.

Rochlin (1993) identificou também alguns indicadores que diferenciavam essas organizações das demais e que puderam ser considerados como próprios das HRO, como: a) busca contínua de melhoria da operação apensar dos altos níveis no desempenho obtidos; b) estabelecimento de metas além das fronteiras do desempenho já conseguido; e c) busca contínua por desempenho e a manutenção da atenção nas operações, mesmo diante da normalidade, orientando os desafios operacionais também em períodos de baixos resultados.

As três organizações estudadas por Gene Rochlin, em Berkley, foram: o sistema de controle de tráfego aéreo dos EUA; uma empresa de eletricidade que opera um sistema de distribuição de eletricidade e uma central nuclear (Diablo Canyon) além de um porta-aviões nuclear da marinha norte-americana. No entendimento de Hopkins (2007), quase toda a literatura sobre HRO deriva dessas três pesquisas. 
Para classificar as organizações consideradas de alta confiabilidade e diferenciá-las das demais, os critérios eram obrigatoriamente simultâneos. Essa obrigatoriedade tem como consequência, no entendimento de Hopkins (2007), a exclusão de seguimentos com potenciais para abrigar organizações altamente confiáveis. Por exemplo, na percepção de Rochlin (1993), todas as operadoras de estrada de ferro são descartadas como HRO porque a tecnologia aplicada nesse sistema são simples e seus riscos limitados.

No entanto algumas características das HRO foram também consideradas válidas por Rochlin (1993) para distinguir as organizações de alta confiabilidade das demais organizações. Essas características dizem respeito à convicção de que as fontes de erro são dinâmicas e que os erros podem acontecer em qualquer lugar. Da mesma forma o ambiente é fonte constante de ameaças, havendo necessidade de manter-se vigilância, renovar e reanalisar os mecanismos de monitoração, adotar redundância para tratar problemas, ser resistente a pressões por agilidade ao implicar riscos, promover a autonomia das unidades de operação, testar sempre os limites da confiabilidade e adotar regras e códigos.

Entretanto outros critérios também são usados para caracterizar as HRO. Neste aspecto, Hopkins (2007) considera que Karl Weick, por não fazer parte do grupo de pesquisadores iniciais da HRT, não se manteve preso aos fundamentos iniciais. Para Kopkins (2007), Karl Weick ateve-se aos pontos mais relevantes para a caracterização das HRO, em vez de considerar quais aspectos estruturais têm uma organização antes de considerá-la confiável, privilegia a forma como uma organização deve agir para ser confiável.

Weick e Sutcliffee (2001), ao examinarem as HRO, apresentam algumas características deste tipo de organização como o modo com o qual conduzem suas operações e como fazem a gestão de seus negócios centrada em cinco princípios básicos: a preocupação com falhas; relutância para simplificar interpretações; sensibilidade às operações; compromisso com a resiliência; e deferência à experiência.

Para Weick e Sutcliffee (2001), nas HRO há efetiva preocupação com as falhas, de modo que qualquer falha é vista como possível causa de problemas no sistema. Seus gestores percebem que pequenos erros separados, mas de ocorrência simultânea, poderão resultar em desastres. A preocupação com falhas é mais efetiva que a busca pelo sucesso. Esses gestores são conscientes que o sucesso pode provocar complacência com falhas, o que conduz a um cuidado ainda maior com o sucesso.

As HRO valorizam os relatórios de erros e os relatórios dos chamados "quase acidentes". Estas organizações consideram que pequenos erros ou falhas podem ser indícios de perigo e de possíveis futuros acidentes. Mesmo os sinais fracos que normalmente provocam reações fracas nas $\mathrm{HRO}$ são considerados importantes e a eles são dedicados maiores cuidados e atenção. A partir de indicadores de perigo, age-se de modo a evitar que os desastres ocorram. Esse é um ponto significativo para distinguir as HRO das demais organizações, porque agem nas fases iniciais, quando ainda é possível evitar os acidentes.

Diante da ambiguidade dos sinais fracos que podem sugerir a ausência de um problema, ainda assim, as HRO analisam esses sinais até que comprovadamente sejam considerados como não representativos de perigo. Esse comportamento das HRO decorre da premissa de que a normalidade não é assumida como padrão.

As organizações, em geral, tendem a simplificar informações em seus processos decisórios, o que implica descartar aquelas consideradas de menor importância. Isto pode levar ao descarte de informações relevantes e necessárias para que acidentes sejam evitados. Na percepção de Weick e Sutcliffee (2001), as HRO relutam em simplificar interpretações e evitam descartar informações que aparentam traduzir normalidade. As situações são analisadas por completo e os detalhes são mantidos. Por considerarem que nada é 
absolutamente compreensível ou previsível, buscam maximizar a percepção das situações analisadas.

As HRO são sensíveis às operações. Dedicam maior atenção quanto à necessidade de se fazerem ajustes continuamente. Neste sentido procura-se evitar o acúmulo de erros ou ampliar o efeito de pequenas falhas. Para Weick e Sutcliffee (2001), as HRO procuram manter as equipes operacionais bem informadas e preparadas em relação às situações de falhas, tanto quanto às possibilidades de falha como aos meios para recuperação. Por evitarem a segregação das equipes, as HRO conseguem com que seja mantido um entendimento mais amplo da operação, possibilitando às equipes uma compreensão maior dos impactos que as diversas ações causam no sistema como um todo.

As HRO têm compromisso com a resiliência. Embora as sejam bastante atentas com as salvaguardas, são também conscientes de que mesmo assim as falhas podem ocorrer e causar um comportamento anormal do sistema. Por essa razão, as HRO estão preparadas para que possam rapidamente recuperar da normalidade sistêmica. Na percepção de Weick e Sutcliffee (2001), a resiliência considera tanto a capacidade em manter o erro em proporções mínimas quanto a criatividade e proatividade em tratar as situações de crise. Para que essa condição seja alcançada, as HRO valorizam as competências e conhecimentos colocando-os em práticas por meio de simulações que visam testar o limite da confiabilidade.

Conforme Weick e Sutcliffee (2001), e em situações anormais nas HRO, as decisões são tomadas na linha de frente, uma vez que a autoridade é delegada às pessoas com a experiência mais adequada para tratar a situação. Em situações normais as decisões podem ser tomadas considerando a estrutura de poder formal, mas em situações especiais, o poder de decisão migra, e uma estrutura contingencial é adotada. Essa condição privilegia a experiência em relação à posição hierárquica.

Ao ressaltar a significância dessa condição, Hopkins (2007) comenta alguns acidentes, como o caso do ônibus espacial Challenger, em que a decisão de autorizar o seu lançamento contrariou a orientação de engenheiros especializados que recomendaram adiar o lançamento. Nesse caso, a tomada de decisões pela Nasa não priorizou a experiência dos especialistas o que teria evitado o acidente e poupado vidas humanas.

Hopkins (2007) exemplifica, destacando o caso da plataforma Piper Alpha -plataforma de extração de petróleo no Mar do Norte, incendiada em 1988, em que o fogo foi alimentado pelo combustível de uma plataforma vizinha. Embora as equipes dessa plataforma vizinha estivessem cientes do que acontecia, não desligaram a produção porque não havia autorização para isso.

Esses exemplos procuram atribuir importância ao princípio de transferência de poder de decisão para aqueles que estão mais bem informados e mais experientes, particularmente quando essas decisões são sobre a interrupção da operação que pode causar ou já estar causando um desastre.

No entanto a questão da migração da tomada de decisão provoca controvérsias, sendo contestada na literatura. Hopkins (2007) reconhece que não está claro quanto o princípio é generalizável. Esse autor menciona evidências de acidentes que ocorreram decorrentes de tomada de decisão, em diferentes níveis das organizações em que aceita como válida a posição de críticos de considerarem que o processo de tomada decisão de baixo para cima pode permitir que pessoas despreparadas ou sem as necessárias informações, possam provocar acidentes. Portanto pode-se inferir que a experiência é fator fundamental na viabilidade de delegar o poder decisões para equipe da linha de frente.

\subsection{Desdobramento dos critérios}


Weick e Roberts (1993) argumentam que a confiabilidade, bem como as condições para se evitar acidentes, dependem da adequação de comportamentos e atitudes da organização. Neste particular, a burocracia é vista como um entrave para que prevaleça o conhecimento especializado nas reações durante a crise, ou mesmo para determinar comportamentos que possam evitar erros ou falhas. Conforme a teoria da HRT, a segurança deve estar promulgada na linha de frente das operações, em que os trabalhadores poderão ter de adotar novos procedimentos e até contornar regras inadequadas para manter a segurança, sobretudo durante uma crise.

No entanto Leveson et al. (2009) discordam da visão da HRT quanto a ênfase na descentralização da decisão. Admitem que os trabalhadores da operação possam ficar autorizados a usarem seus conhecimentos e julgamentos para manter a segurança ou a confiabilidade em situações particulares de crises. A discordância é em relação à suposição de que os trabalhadores operacionais têm conhecimento e discernimento suficientes para tomada de decisão, o que consideram não ser verdadeiro.

Há casos em que os operadores desconsideraram procedimentos inseguros e assim conseguiram impedir acidentes, como foi destacado por Perrow (1999) e Hopkins (2007). Por outro lado, Leveson et al. (2009) observam que também há situações em que os operadores, ao terem ignorado procedimentos, acabaram causando acidentes. No entendimento dos mesmos autores é mais adequado padronizar os procedimentos de emergência e manter os trabalhadores familiarizados e treinados com esses procedimentos. Para proporcionar segurança, Leveson et al. (2009), defendendo a necessidade de uma visão do todo, argumentam que são necessárias informações na perspectiva sistêmica, o que fica prejudicado quando o processo de decisão está descentralizado, e da mesma forma, as decisões também precisam ser aplicadas no nível do sistema, contrapondo-se à aplicação pontual.

Em termos de segurança e confiabilidade, a expectativa das pessoas tem importância. Segundo Weick e Sutcliffee (2001), quando as pessoas esperam por algo, elas direcionam sua atenção e recursos para o que é então esperado. A tendência é que as pessoas passam a procurar evidências que confirmam suas expectativas e acabam se tornando menos sensíveis aos sinais que contrariam essas expectativas. Em situações de crises, quando as pessoas estão sob tensão, o problema pode ser agravado, tornando-se um fator crítico no desenvolvimento de um possível acidente.

As surpresas desagradam por evidenciar a incapacidade de controle em função das previsões feitas. Algumas vezes um problema foi reconhecido, mas a direção da expectativa estava errada; outras vezes é conhecido o que irá ocorrer, mas ocorre em momento distinto do esperado. Em outras situações, o que surpreende não é o evento, mas sua duração, de modo que o que devia ser transitório mostra-se duradouro. Há ainda situações em que o problema é esperado, mas é sua magnitude que surpreende (WEICK; SUTCILIFFEE 2001).

Leveson et al. (2009) ressaltam que não há garantia que as práticas adotadas pelas HRO possam produzir resultados equivalentes em outras situações. Esses mesmos autores argumentam que essas organizações têm particularidades que possibilitam a eficácia das práticas, mas que são de difícil aplicação em outras organizações. As decisões são suportadas por pleno conhecimento de condições operacionais e técnicas quanto à percepção e compreensão do perigo. As pessoas são bem informadas sobre todo o contexto técnico daquilo com que estão trabalhando e evitam acomodar-se supondo estarem preparados para qualquer contingência. Concluem então que algumas propriedades dos sistemas das HRO não são aplicáveis em qualquer sistema.

\subsection{Barreiras e defesas sistêmicas}


Os acidentes são causados por uma série de fatores em cadeia a partir de um erro ou falha que deu início a uma propagação. Raramente um desastre é resultado de uma falha isolada. Como destacam Bolman e Deal (2003), os sistemas possuem um conjunto de barreiras que objetivam evitar, monitorar e detectar possíveis falhas ou erros, inibindo, dessa forma, a propagação por todo o sistema. No entanto ressaltam os mencionados autores que essas barreiras tornam-se também componentes do sistema, aumentando a complexidade e tornando-se elas próprias causa de novas falhas ou erros.

Processos estruturados possuem redundância de controles preventivos e pontos de verificação que permitem identificar anomalias. Esses controles redundantes são independentes um do outro. $\mathrm{O}$ desastre ocorrerá quando sistemicamente o processo falhou, e não apenas uma falha isolada (BOLMAN; DEAL 2003).

As barreiras são fundamentais e se apresentam como defesas sistêmicas em forma de alarmes, desligamentos automáticos, travas, acionadores de verificações pessoais por operadores, controles, procedimentos, etc. Entretanto, como observa Reason (2001), sempre haverá fraquezas e lacunas que se apresentam de forma dinâmica nas barreiras de defesa. As barreiras se apresentam em redundância e por formas distintas. Assim, como elas próprias são sujeitas a falhas, quando uma barreira falhar, outras cumprirão a finalidade de impedir ou denunciar a eminência de alguma falha. Os acidentes ocorrem em geral quando essas barreiras falham simultaneamente. Por essa razão, quando ocorrem os acidentes, raramente são decorrentes de uma única falha, mas de uma combinação de falhas.

\section{CONSIDERAÇÕES FINAIS}

A literatura na área da teoria das organizações tem destacado a relevância de critérios de medição de desempenho como a eficiência e eficácia organizacionais. Mais recentemente, estudiosos nessa área trouxeram para a discussão um tema que afeta organizações complexas cujas operações implicam grandes riscos e são sujeitas a falhas com resultados desastrosos para operadores, gestores e ao meio ambiente, além da própria sociedade. Exemplos desse tipo de organização são as usinas atômicas, companhias aéreas, minas, sistema de controle de voos e indústrias químicas, entre outros.

Diante da complexidade do mundo atual, o tema confiabilidade organizacional, ainda tão pouco estudado, ganha maior atenção na mídia e maior espaço na literatura da área. Os acidentes com sistemas complexos costumam provocar grandes impactos, e olhares desavisados podem conduzir a uma percepção equivocada a respeito dos fatos e das causas desses acidentes.

É crescente a necessidade da sociedade de produtos e serviços cada vez mais sofisticados e dependentes de alta tecnologia. A natureza desses produtos e serviços e a complexidade do sistema de produção, caracterizado como sistema sociotécnico, conduzem à falhas ou acidentes no processo produtivo com repercussões indesejáveis às organizações, aos seus integrantes, assim como ao meio ambiente e à sociedade.

As organizações às quais se confere alta confiabilidade seguem princípios que orientam suas práticas para a contínua preocupação com as falhas e com o aperfeiçoamento operacional, atribuem importância à experiência e ao aprendizado organizacional e são relutantes em simplificar interpretações. No entanto é o comportamento dessas organizações altamente confiáveis que desponta como relevante para efetividade dos princípios adotados. Esse comportamento resulta da consciência de que seus produtos e serviços, além de essenciais, decorrem de sistemas de alto grau de complexidade e de elevado risco em suas operações. 
A condição de altamente confiável é uma questão eminentemente situacional. Cada organização busca sua forma de estruturar-se e de agir objetivando a confiabilidade de sua operação. Por esta condição, infere-se que formulações prescritivas, quando pressupõem a generalização ou padronização de práticas, tendem à ineficácia por desconsiderarem particularidades que dão sentido ao comportamento organizacional.

Conhecer melhor os sistemas complexos e implicações caracterizadas pela Normal Accidents Theory (NAT) (Charles Perrow) e High Reliability Theory (HRT) (Karl Weick), contribui para seu melhor gerenciamento e para uma maior compreensão das condições e comportamentos que em suas operações levam uma organização a ser considerada altamente confiável. Desta forma, se estará trazendo efetiva contribuição ao evitar acidentes que se desdobram em desastres, com graves consequências para as organizações e, especialmente, à sociedade por afetar vidas humanas e o meio ambiente.

\section{REFERÊNCIAS}

BOLMAN, Lee; DEAL, Terrence. Reframing Organizations: artistry, choice, and leadership. San Francisco: Jossey-Bass Publishers, 2003.

ETZIONI, Amitai. Organizações modernas. Tradutora: LEITE, Miriam. 8. ed. São Paulo: Pioneira, 1989.

GERSHENSON, Carlos; HEYLIGHEN, Francis. Haw can we think complex? In: Managing organizational complexity: philosophy, theory and application. Editor: RICHARDSON, Kurt. Greenwich: IAP, 2005

GILPIN, Dawn R. A complexity-based scrutiny of learning from organizational crisis. In: Managing organizational complexity: philosophy, theory and application; Editor: RICHARDSON, Kurt. Greenwich: IAP, 2005.

HOPKINS, Andrew. The problem of defining high reliability organisations. The National Research Centre for Occupational Health and Safety Regulation, Canberra: The Australian National University, 2007.

JOSLIN MEDEIROS, Janann; PINTO, Wellington. Organizações de alta confiabilidade e administração de risco operacional, BBR Brazilian Business Review, v. 6, n. 2, Fucape Business School, p.174-190, maio/ago. 2009.

LEVESON, Nancy; DULAC, Nicolas; MARAIS, Karen; CARROLL, John. Moving beyond normal accidents and high reliability organizations: a systems approach to safety in complex systems. Organization Studies, n. 30, p. 227-249, fev./mar. 2009.

MEYER Jr., Victor. A escola como organização complexa. In: Eying, A. e Ghisi, M.L. Políticas e gestão da educação superior. 2007.

MORGAN, Gareth. Imagens da organização. São Paulo: Atlas, 1996.

MORIN, Edgar. Ciência com consciência. 7. ed. Rio de Janeiro: Bertrand, 2003. 
ORTON; J. D.; WEICK, Karl. Loosely coupled systems: a reconceptualization. The Academy of Management Review, v. 15, n. 2, abr. 1990.

Perrow, C. Normal accidents: living with high risk technologies. New York: Basic Books, 1999.

PERROW, Charles. A personal note on normal accidents. Organization \& Environment, n. 17, p. 9-14, mar. 2004.

PRIM, Carlos H. et al. A teoria das organizações e a evolução do pensamento científico. XXXII encontro EnANPAD, Rio de Janeiro: 2008.

QUINELLO, Robson; NUNES, Rogério. Ambientes complexos vulnerabilizados pela memória e esquecimento das organizações. Revista de Negócios, Blumenau, v. 9, n. 3, p. 135-146, jul./set. 2004.

REASON, J.; CARTHEY, J.; LEVAL M. Diagnosing "vulnerable system syndrome”: an essential prerequisite to effective risk management. Quality in Health Care, n. 10, Suppl II, p. ii21-ii25, 2001.

ROCHLIN, G. Defining "high reliability" organizations in practice: a taxonomic prologue. In: Roberts, K. New Challenges to Understanding Organizations. New York: Macmillan, 1993.

SEGAN, Scott D. The limits of safety: organizations, accidents and nuclear weapons. Princeton: Princeton University Press, 1995.

SERVA, Maurício. O paradigma da complexidade e a análise organizacional. RAE - Revista de Administração de Empresas. São Paulo: v. 32, n.2, p. 26-35, abr./jun. 1992.

SEVERINO, Antônio. Metodologia do trabalho científico. 23. ed. São Paulo: Cortez, 2007.

TRAGÉDIA do vôo 1907. Produção de Alan Tomlinson. Discovery Channel, 2007.

USP. Orientações para o envio de ensaios teóricos. $\mathbf{1 1}^{\circ}$ Congresso controladoria e contabilidade. São Paulo: EAC-FEA/USP, 2011. Disponível em www.congressousp.fipecafi.org/ensaios-teoricos.asp acessado em $1^{\circ}$ mar. 2011.

WEICK, Karl. Educational organizations as loosely coupled systems. Administrative Science Quarterly, v. 21, p. 1-19, 1976.

Weick, Karl; ROBERTS, Karlene. Collective mind in organizations: heedful interrelating on flight Decks. Administrative Science Quarterly. v. 38, n. 3, p. 357-381, 1993.

WEICK, Karl; SUTCLIFFEE, Kathleen. Managing the unexpected. John Wiley \& Sons, 2001. 